\title{
Response: Let This Be an Example: Three Remarks on a Thematic Cluster about Climate Change Exemplarity
}

\author{
By Hall Bjørnstad
}

This thematic section of Culture Unbound brings together five articles which in very different ways invite us to reflect on the importance of examples in the discourse on climate change. At first glance, such an invitation might be surprising, if not puzzling. Anthropogenic climate change is something radically unprecedented, so it would seem counter-intuitive to approach it through the discussion of prior examples. Furthermore, the analytical vocabulary which is already mobilized in the title of the section (exemplarity) and the introduction (exemplification) may seem alien to most readers. Do these terms actually serve as precise conceptual tools in the analysis? Indeed, is there really something like an operative theory of examples? To my mind, the five articles gathered here are very successful in dispelling such an initial reticence. Each piece is rich and thought-provoking on its own terms. Moreover, taken together, these articles help us appreciate the extent to which the use of examples is an unexpected and promising index for mapping how climate change discourse navigates between effect and affect, between illustration and ideal, between facts and values, between science and politics. In so doing, this thematic section also provides tools for better grasping the power of examples as such, which should be of methodological interest for other fields of study.

In what follows, I will briefly comment on three aspects that I not only found particularly intriguing, but which are illuminated differently according to the shifting perspectives of the case studies in the articles. First, the surprising emphasis on the archive in certain articles; second, the position of exemplarity and exemplification between theory and practice; and third, the meaning of the deep desire for potent examples of climate change in the wider society, which will, in closing, bring me back to the title of my response.

Keywords: climate change, exemplarity.

Bjørnstad, Hall : "Response: Let This Be an Example: Three Remarks on a Thematic Cluster about Climate Change Exemplarity”, Culture Unbound, Volume 11, issue 3-4, 2019: 415-420. Published by Linköping University Electronic Press: http:// www.cultureunbound.ep.liu.se 


\section{An archive from the deep past}

None of the articles in the volume contests that present-day anthropogenic climate change is radically unprecedented. All the same, three of them explore cases where examples mobilized in climate change discourse are gathered from archives with roots in a remote past. This is first of all a central element in John Ødemark's close analysis of the momentous 1987 UN report Our Common Future, which still informs the current UN approach to sustainable development. If sustainable development is more than an oxymoron, it is through the "living example of sustainable living" provided by what the report terms "indigenous and tribal peoples." As such, their presence supplements a lack in the actual historical archive, a presence of the deep past in the present. We meet another pre-historic archive but with a very different temporality in Henrik H. Svensen, Marit Ruge Bjærke and Kyrre Kverndokk's exploration of how a period of rapid global warming 56 million years ago, the so-called Paleocene-Eocene Thermal Maximum (PETM), is used as an example related to our current predicament across different scientific genres. Scientifically speaking, the "sedimentary archive" of the PETM yields conclusions too uncertain to inform actual climate change modelling, yet, as the authors demonstrate, when considered as an example, it is still found to be both qualitatively and morally significant. Here, too, the archive from the deep past seems to speak with an unexpected authority. The third article that explores a case where examples from the remote past carry considerable argumentative authority in discussions of climate change differs insofar as the case itself is situated in the past. More specifically, Anne Eriksen explores a baffling eighteenth-century proposal of ways in which humans could improve the climate in Norway. The author of the 1758 proposal, Gerhard Schøning was himself a historian, and the argument relies almost entirely on examples from ancient Greek and Roman history. In the context of our discussion here, Schøning's proposal is noteworthy as the most striking example of the power of example: the deforestation of a whole country based on the authority of an historical archive dating two thousand years back.

How could such an argument, about such radical action based on such remote sources, possibly be convincing? The question is all the more important since taken as a whole, this thematic section on climate change exemplarity seems to suggest that a weaker version of the same argument is at play elsewhere, starting with the two other cases just mentioned where inference for the present is made on the basis of examples taken from the archive of a deep past. As the authors of the article on the exemplarity of the PETM suggest, there are formal similarities between their case and "the early modern historia magistra vitae topos." History was considered the teacher of life, or in Eriksen's formulation: "History consisted of examples to learn from and models to follow." This was an age before the modern conception of progress, in which the future was expected to resemble the 
past. A premodern culture of exemplarity which is no longer ours and in which the archive from the past imposed itself with an authority, a normative magisterial force difficult for us to understand today. In my reading, this difficulty and this effort to understand are at the core of the enterprise of the five articles taken as a whole. Therefore, while at the outset Eriksen's case study of eighteenth-century climate change exemplarity might seem like an outlier, it is in reality the linchpin of the whole project, itself a mirror from the past, showing us today how the past used to be a mirror for the present.

\section{Towards a theory of examples?}

The inclusion of examples in discourse is a way of buttressing what we are saying. Obviously, this is the case even in the articles gathered in this volume (and in my response). However, a different means to the same end, particularly attractive in academic discourse, is the practice of referring to established theory. Whereas the example is unruly practice, theory nails downs aspects of truth in affirmative observations. Or, at least, so we like to think. But is there, can there be a theory of examples? The articles under consideration here seem to indicate that this is the case. At crucial moments throughout, they mention "example theory" or "theories of exemplarity." Furthermore, there are a couple of references to - and even a few key quotations from - such a "theory" that circulate between the articles, as a common doxa, a stable ground on which to build. However, as somebody who has worked extensively on issues related to early modern exemplarity myself, I would respectfully surmise that this is not exactly a theory that provides a common foundation. Rather, these quotations are illuminating intuitions, flashes of insight in need of further development; starting points for reflection, rather than established theory. One could even wonder to what extent the two scholars who are the most often quoted (Alexander Gelley and John D. Lyons) had theoretical ambitions in their exploration of the workings of exemplarity. That would of course depend on what one means by theory, but it would hardly be a theory of any synthesizing, systematizing kind, with the pretention of having fully explained and exhausted the phenomenon. It is significant in this respect that both Gelley and Lyons are scholars informed by post-structuralist thought and so-called "critical theory." In their actual analysis of discourse they are more "critical" than "theoretical," in the sense that they are drawn towards moments where examples become "unruly" (the title of the important collective volume edited by Gelley) and instances that confirm Montaigne's famous assertion that "all examples are lame" (expertly analyzed by John Lyons). If there is a theory of examples and of exemplarity, it lies elsewhere.

However, if what I am saying here is a critique of the methodological approach of the volume, the weakness I am pointing out is the quite minor sin of ex- 
ceeding humility. In fact, the most sophisticated and comprehensive discussion of the power of example that I know of is written not by Gelley or Lyons, but by Anne Eriksen et al, although the text, a book chapter entitled quite simply "Eksemplets makt" [the power of example], is unfortunately not yet available in English. In the absence of an English version of this crucial piece, the work performed collectively by the six texts in the present volume (including the introduction) is among the most important contributions - not exactly to a theory of the use of examples, but towards a better understanding of the way examples worked and didn't work in the past and still today. This is particularly the case with the discussion of the exemplarity of the PETM in the article by Svenden, Bjærke and Kverndokk, and Eriksen's discussion of Schøning's astonishing project, as referred to above, but also with many other instances in the volume.

\section{Exemplifying climate change, now}

The two articles that most directly and literally explore climate change exemplarity in contemporary debates are the single-authored pieces by Bjærke (on species extinction) and Kverndokk (on extreme weather). They are quite different in orientation from the three other articles in that they consider the process of exemplifying climate change in the present while looking towards the future. Rather than examples that serve to make the past present, they study examples whose power comes from evoking the presence of the future.

Here, it is worth taking a step back to recall the radical need for exemplification in climate change discourse. As the editors remind us in the introduction, climate change as such is not directly observable. Therefore, the mediation that would enable the passage from "silent" scientific numbers to more widely accessible narratives relies on a process of visualization, concretization, manifestation. The perceived urgency of the situation calls for a tangible and striking example, whereas scientific facts remain abstract and remote. An example that not only stands for climate change, but which stands out, and spectacularly so, with the potential to capture the imagination of a wide array of concerned citizens. This is very much the case in the two situations studied here. In fact, when extreme weather (Kverndokk) or species extinction (Bjærke) are mobilized as examples of climate change, they risk working too well. In other words, as expressed in the title of the two articles: these examples certainly make the invisible visible, even extremely visible, but in the process exemplification too risks running amok. In the specific materials analyzed, the authors identify a tendency in mass media coverage to diagnose climate change as the culprit too quickly, at the risk of erasing local differences and complexity. This exemplification is much more than mere examples, in the sense of illustrations, or more or less random samples. Episte- 
mologically speaking, it does not lead to scientific proof, but rather to examples that themselves take part in shaping the cultural meaning of climate change. These examples are not science, but, in a certain sense, they are truer than science, as warnings about things to come. Present-day loss and destruction evoking a nightmarish apocalyptic scenario of much worse catastrophes that lie ahead.

There is a duality in the term example itself which allows for the conceptual richness explored here in terms of exemplification and exemplarity. The example can be, on the one hand, a plain illustration, a sample, one of many in a series, but, on the other hand, also something marked as exemplary and worthy of imitation. As such, it brings together fact and value, knowledge and politics in a way which is difficult to nail down. However, in these scholarly discussions of the workings of examples, there is a negative meaning which always resonates but is never made explicit, probably because it would complicate the unruly discussion even further. Here is the fourth definition of example in the Oxford English Dictionary: "An act or instance of punishment or retribution intended to deter others from committing the act for which the punishment or retribution is inflicted; (also) a person whose fate may serve as a warning to others against a particular act, course of action, etc. Also as a mass noun: warning, deterrent." The typical dry and understated language of a modern dictionary (passive voice, laconic tone, absence of agency) contrasts well with the somber meaning. For now, the force is held back, as is this negative meaning itself in the title "climate change exemplarity," hidden by the uplifting, edifying lilt of "exemplarity." But only for so long. The spectacular example of climate change returns. A punishment that mankind brought upon itself. Nature emitting one last warning or deterrent in the form of the pre-apocalyptic catastrophe which is ours: Let this be an example.

Hall Bjørnstad is Associate Professor of French at Indiana University Bloomington, where he also directs the interdisciplinary Renaissance Studies Program. He is the author of Créature sans créateur: Pour une anthropologie baroque dans les "Pensées" de Pascal (Presses de l'Universite Laval, 2010; Hermann Éditeurs, 2013); co-editor, with Helge Jordheim and Anne Régent-Susini, of Universal History and the Making of the Global (Routledge, 2018), co-editor, with Katherine Ibbett, of Walter Benjamin's Hypothetical French Trauerspiel (Yale French Studies vol. 124, 2014); and the editor of Borrowed Feathers: Plagiarism and the Limits of Imitation in Early Modern Europe (Oslo, 2008). He is currently finishing a book project that explores changing expressions of royal exemplarity in Early Modern France. 


\section{References}

Eriksen, Anne, Ellen Krefting and Anne Beate Rønning (2012): "Eksemplets makt," Anne Eriksen, Ellen Krefting and Anne Beate Rønning (eds.): Eksempelets makt: Kjønn, representasjon og autoritet fra antikken til i dag. Oslo: Scandinavian Academic Press, 9-38.

Gelley, Alexander (1995): “Introduction,” Alexander Gelley (ed.): Unruly Examples: On the Rhetoric of Exemplarity. Stanford: Stanford University Press, 1-24.

Lyons, John D. (1989): Exemplum: The Rhetoric of Example in Early Modern France and Italy. Princeton: Princeton University Press.

Oxford English Dictionary. <www.oed.com> (accessed 1/4/20). 